\title{
Frodo and Darius: South African potato cultivars with good processing quality
}

\author{
J.M. Steyn ${ }^{1^{*}}$, E.B. Geremew ${ }^{1}$, J.G. Annandale ${ }^{1}$ \& P.J. Steyn ${ }^{2}$ \\ ${ }^{1}$ Department of Plant Production and Soil Science, University of Pretoria, Pretoria 0002, South Africa. \\ ${ }^{2}$ McCain Foods (SA) (Pty) Ltd, P.O. Box 31023, Delmas, 2210, South Africa.
}

Accepted 5 January 2009

\begin{abstract}
Two newly released South African potato cultivars, Frodo and Darius, were compared with two foreign processing cultivars, Pentland Dell and Shepody. The cultivars were grown under sprinkler irrigation and evaluated for external and internal tuber characteristics and processing quality. The experiment was conducted at Bronkhorstspruit, South Africa. Results indicated that Frodo had significantly higher tuber form index values (long tuber shape) for all tuber sizes, a desired characteristic for french fry processing. Pentland Dell and Shepody exhibited more vascular discolouration, while Frodo had the highest occurrence of tuber brown spot. These physiological disorders probably resulted from unfavourably high temperatures and water stress during the late growing season. Shepody had the lowest specific gravity, followed by Pentland Dell. Reducing sugar levels for both the foreign cultivars were also relatively high and only marginally within the ranges required for french fry processing. Frodo and Darius, on the other hand, had high specific gravities and low reducing sugar levels, which are desirable characteristics for long-term storability and the production of quality frozen fries. Tuber yields of these two cultivars were also similar or higher than those of the foreign cultivars. Frodo and Darius can, therefore, successfully compete with Shepody and Pentland Dell as processing cultivars under local conditions.
\end{abstract}

Keywords: Fry colour, reducing sugar, specific gravity, tuber characteristics

*To whom correspondence should be addressed (martin.steyn@up.ac.za)

\section{Introduction}

The production of high quality potatoes depends on the cumulative effect of various factors, including the genetic make-up of cultivars, the climate and the physical and biological properties of the soil (Brown, 1993). External and internal tuber characteristics affect the final processing quality of tubers. According to David et al. (1983), high quality tubers should be turgid, well shaped and uniform in size. In addition, tubers destined for processing should be free from adhering soil, mechanical damage, greening, sprouts, disease and physiological defects (David et al., 1983). Quality traits important for cultivars used in potato chip manufacturing include high dry matter content (or high specific gravity), low reducing sugar levels and being free from defects (Hayes \& Thill, 2002).

The development of brown chip colour upon frying is the result of reactions between amino acids and reducing sugars (glucose and fructose) (Hayes \& Thill, 2002). The lower the content of reducing sugars in tubers, the lighter and more acceptable the chip colour (Gary \& Hughes, 1978).

Specific gravity of tubers is an important determinant of processing quality. This tuber attribute is an indicator of maturation, and is used by the industry to judge fry quality, baking characteristics and storability (Hayes \& Thill, 2002). The specific gravity of tubers is directly correlated to their dry matter content. The higher the dry matter content, the lower the water content and the higher the specific gravity. When tubers with high water content are processed into french fries, approximately two-thirds of the water is replaced by oil during frying (Mosley \& Chase, 1993). Therefore, tubers with high water content or low dry matter content produce oily and soggy french fries, as more water has to be removed during processing (Mosley \& Chase, 1993). Processors and consumers consider the ideal french fry as light in colour, crisp on the outside and mealy on the inside, with minimum oiliness. Gen- erally, a specific gravity of 1.075 and higher is considered acceptable for french fry production (Somsen et al., 2004).

High tuber yield of high specific gravity is usually directly related to the length of the growing season of a cultivar. Early maturing cultivars typically have short storage dormancy and are usually processed at harvest or shortly thereafter. Cultivars that are relatively late maturing usually have long storage dormancies and can be processed over several months (Hudson, 1975; Mosley \& Chase, 1993; Baritelle \& Hyde, 2003).

In addition, tuber specific gravity reflects environmental factors and cultural practices, such as fertiliser and soil water management during the production season (Baritelle \& Hyde, 2003). Excess nitrogen, or excessive or insufficient soil water, particularly when accompanied by high temperatures, can lower specific gravity (Hegney, 2001; Baritelle \& Hyde, 2003; Stark et al., 2003; Tourneux et al., 2003).

External and internal tuber defects like malformation, brown centre and hollow heart, can substantially reduce the processing quality of tubers. These defects depend on the cultivar, environment and management during the growing season. Proper water management during the growing period is especially crucial for high yield and a high chipping standard of tubers. Water stress during tuber initiation and early tuber development can substantially reduce tuber quality by increasing the proportion of malformed tubers (Steyn et al., 1992; Shock et al., 1998). Low soil water content, especially when the crop is close to maturity, as well as rapid death of vines due to frost, mechanical destruction or high temperature stress, can result in vascular discolouration (Pavlista, 2002). Growth disorders such as brown centre and hollow heart are mostly associated with an abrupt change in growth conditions during the season (Hochmuth et al., 2001). Excessively rapid tuber growth after a cool period and / or soil water stress aggravates the formation of brown centres and hollow hearts 
(Hochmuth et al., 2001). McCann \& Stark (1989) also report an association of stem-end hollow heart with potassium deficiency. The extent of tuber quality deterioration due to unfavourable environmental and growing conditions depends largely on inherent cultivar characteristics.

Frodo and Darius, the two newly released potato cultivars included in this study, were developed by the Agricultural Research Council (ARC-Roodeplaat) of South Africa. When these experiments were conducted, Frodo was still a breeding line, but was subsequently released as a cultivar. Frodo is a high-yielding medium-late maturity cultivar with long tubers and good processing characteristics. Darius has a medium maturity length, long-oval tuber shape with shallow eyes, and white skin and flesh. This cultivar produces a high yield with good tuber size distribution and high specific gravity, desirable characteristics for french fries and crisping (Visser, 2003).

Pentland Dell was developed in the United Kingdom for its high yielding ability and good processing quality (Van Niekerk, 1984). Shepody, on the other hand, was developed in North America as a medium to high yielding processing cultivar (CSIDC, 2003).

Potato processors prefer cultivars that will ensure consistency of supply and maintain superior processing quality. Tuber yield, size distribution, morphological attributes, external and internal deformities, specific gravity, and reducing sugar levels are factors affecting recovery percentage, fry colour, and quality. The objective of this study was to characterize the growth, yield and processing characteristics of the newly released potato cultivars Frodo and Darius in comparison with two established processing cultivars, Pentland Dell and Shepody for local conditions.

\section{Materials and methods}

\section{Site description}

The study was conducted from August 2003 to January 2004 at the McCain experimental station near Bronkhorstspruit, South Africa. The station is located on $25^{\circ} 44^{\prime} 16^{\prime \prime} \mathrm{S}, 28^{\circ} 41^{\prime}$ 3" E and at an elevation of 1490 m.a.s.l. The total water supplied (rainfall and irrigation) during the growth period was $636 \mathrm{~mm}$ for the early maturing cultivar, Shepody, $684 \mathrm{~mm}$ for Pentland Dell and $817 \mathrm{~mm}$ for Frodo and Darius. The daily mean maximum temperature during the crop growth period was $26.4{ }^{\circ} \mathrm{C}$ (median $27.3{ }^{\circ} \mathrm{C}$ and range from $16.6{ }^{\circ} \mathrm{C}$ in October to $32.2{ }^{\circ} \mathrm{C}$ in December), while the average daily minimum temperature was $13.7^{\circ} \mathrm{C}$ (median $15.4{ }^{\circ} \mathrm{C}$ and range from $7.9^{\circ} \mathrm{C}$ in October to $18.4{ }^{\circ} \mathrm{C}$ in December).

\section{Field procedure and treatments}

The trial, which included the four potato cultivars Frodo, Pentland Dell, Darius and Shepody, was planted on 28 August 2003. Each cultivar occupied six rows of $9 \mathrm{~m}$ long, at a spacing of $0.9 \mathrm{~m}$ between rows and $0.3 \mathrm{~m}$ between plants within the row, giving a plot size of $48.6 \mathrm{~m}^{2}$. The experiment was arranged in a randomised complete block design with three replicates. The experimental field was kept free of weeds and standard disease and pest control measures were followed.

At planting the crops received $80 \mathrm{~kg} \mathrm{ha}^{-1} \mathrm{~N}, 120 \mathrm{~kg} \mathrm{ha}^{-1} \mathrm{P}$ and $160 \mathrm{~kg} \mathrm{ha}^{-1} \mathrm{~K}$ in a 2:3:4 (30) fertiliser blend. Three applications of limestone ammonium nitrate (LAN, $28 \% \mathrm{~N}$ ) were side-dressed from 50 to 80 days after planting, which resulted in a total nitrogen application of $220 \mathrm{~kg} \mathrm{ha}^{-1}$. Rows were ridged directly after the first nitrogen side dressing. No nutrient deficiency symptoms were observed throughout the crop growth period.

Table 1 External tuber characteristics evaluated for four potato cultivars (USDA, 1997)

\begin{tabular}{lcl}
\hline Tuber characteristics & Score & Explanation \\
\hline Secondary growth & 1 & no tubers \\
Malformation & 2 & $<10 \%$ tubers \\
Mechanical damage & 3 & $10-30 \%$ tubers \\
Growth cracks & 4 & $30-60 \%$ tubers \\
\hline Stolon indent & 5 & $>60 \%$ tubers \\
Eye depth & 1 & Superficial \\
& 2 & Medium depth \\
\hline & 3 & Deep \\
Skin colour & 1 & White \\
& 2 & Yellow \\
& 3 & White with markings \\
\hline
\end{tabular}

\section{External and internal tuber characteristics}

At harvest, specific gravity (SG) and reducing sugar content (as indicator of french fry colour) were determined on samples of large and medium-sized tubers randomly selected from each plot. For SG determination, tubers were weighed in air (Ma) and water (Mw). The SG was calculated using the following formula (USDA, 1997):

$$
\mathrm{SG}=\mathrm{Ma} /(\mathrm{Ma}-\mathrm{Mw})
$$

The reading obtained for each SG test was corrected for temperature variations according to the standards provided by the USDA (1997). Reducing sugar contents were determined according to USDA (1997) standards for chipping quality 
potatoes. Tuber form index (TFI) was determined for tubers in the large, medium and small size categories. Tubers were categorised as large when their diameter (width) was greater than $75 \mathrm{~mm}$, medium when it was between 55 and $75 \mathrm{~mm}$, and small when less than $55 \mathrm{~mm}$. For each category, length, width and mass of tubers were measured and the TFI was computed as:

$$
\text { TFI = Length / Width }
$$

The scoring methods used and their respective values for external tuber characteristics are given in Table 1, and for internal tuber characteristics, in Table 2.

Table 2 Internal tuber characteristics used for evaluating four potato cultivars (USDA, 1997)

\begin{tabular}{|c|c|c|}
\hline Tuber defects & \multicolumn{2}{|c|}{ Score and explanation } \\
\hline \multicolumn{3}{|l|}{ Hollow heart } \\
\hline Brown spot & \multicolumn{2}{|c|}{$\%$ of tubers with defect } \\
\hline \multicolumn{3}{|l|}{ Vascular discolouration } \\
\hline Tuber defects & Score & Explanation \\
\hline \multirow{5}{*}{ Dry rot } & 1 & no tubers \\
\hline & 2 & $<10 \%$ tubers \\
\hline & 3 & $10-30 \%$ tubers \\
\hline & 4 & $30-60 \%$ tubers \\
\hline & 5 & $>60 \%$ tubers \\
\hline \multirow[t]{3}{*}{ Tuber defects } & Score & Presence and $\%$ of tuber surface area \\
\hline & 1 & no tubers \\
\hline & 2 & $1-25 \%$ \\
\hline \multirow{3}{*}{$\begin{array}{l}\text { Common scab (area) } \\
\text { Eelworm (root knot) }\end{array}$} & 3 & $25-50 \%$ \\
\hline & 4 & $50-75 \%$ \\
\hline & 5 & $75-100 \%$ \\
\hline Tuber characteristics & Score & Explanation \\
\hline \multirow{4}{*}{ Flesh colour } & 1 & White \\
\hline & 2 & Cream \\
\hline & 3 & Light yellow \\
\hline & 4 & Intense yellow \\
\hline
\end{tabular}

\section{Statistical analysis}

An analysis of variance was performed using the SAS for Windows (2002). Means were compared using the least significant difference (LSD) test at a $95 \%$ probability level. Correlation between parameters was performed where applicable.

\section{Results and discussion}

Growth, dry matter partitioning and tuber yield results were earlier reported by Geremew et al. (2007). Tuber yield results indicated that Frodo and Darius had similar or higher yields than the two foreign cultivars. This paper reports on the genotypic differences observed in specific gravity, reducing sugar content, and external and internal tuber characteristics as indicators of desired processing quality.

Specific gravity gives an indication of crop maturity, harvest quality and storability of tubers. Specific gravity is directly proportional to dry matter content (Belanger et al., 2002), and therefore directly influences processing quality. In practice, this attribute is the indicator used to judge fry quality and storability (Shetty, 2005). For the cultivars compared in this experiment, Shepody had a significantly lower mean specific gravity (1.069) than the other cultivars (Figure 1). According to Mosley and Chase (1993), specific gravity val- ues between 1.060 and 1.069 are regarded as low, while values of 1.070 to 1.079 are medium and 1.080 to 1.089 are regarded as high. High specific gravities are required for quality chips and french fries.

The specific gravities of early-maturing cultivars are reported to be typically lower than those of late-maturing cultivars (Belanger et al., 2002). Shepody is an early-maturing cultivar (Hutchinson et al., 2001), compared to Frodo, Pentland Dell and Darius, which might partially explain its lower specific gravity (and much lower tuber yields) in this study. Hutchinson et al. (2001) also reported that this cultivar has a moderate to low specific gravity, compared to other processing potato cultivars, under North American conditions. The very low specific gravity of this cultivar under local conditions suggests that it may not be ideal for processing into fries, as it may become soggy due to its low dry matter content. Shepody should be suitable for pan frying, salads, boiling and canning. Pentland Dell tubers had an intermediate mean specific gravity of 1.078 (Figure 1), which is expected to produce fair to good chipping qualities. In South Africa, this cultivar is widely produced in the central interior regions of Mpumalanga for the chipping industry (Van Niekerk, 1984). 


\section{血 Reducing sugars (\%) ■ Specific gravity}

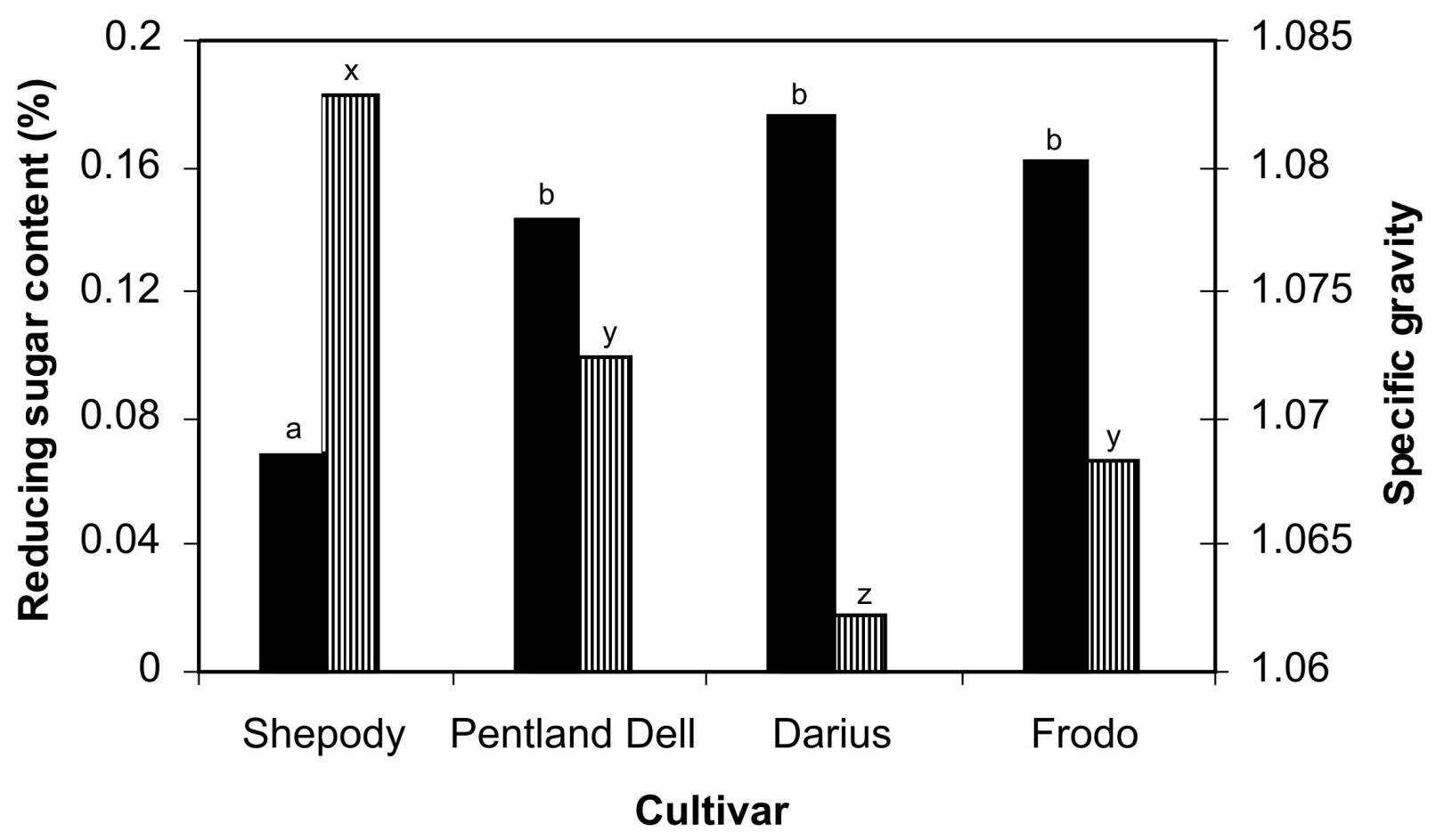

Figure 1 Reducing sugar content (\% fresh mass basis) and tuber specific gravity of four potato cultivars

Frodo and Darius, the late maturing cultivars, had high specific gravity values of 1.080 and 1.082, respectively (Figure 1). When processed, these tubers are expected to produce fries of acceptable mealy and dry texture. It should also be possible to store the tubers for several months, with low risk of deterioration in processing quality.

Specific gravity is not only a cultivar characteristic, but is also influenced by factors such as water supply during the growing season. Potatoes are especially sensitive to water stress during tuber initiation and development (Steyn et al., 1992; Shock et al., 1998). Excess or insufficient soil water, particularly when accompanied by high temperatures, can lower specific gravity (Baritelle \& Hyde, 2003; Stark et al., 2003). In South Africa, potatoes are often grown under unfavourable temperature and short daylight conditions, which are known to affect growth, yield and tuber quality (Visser, 2003). The extent of tuber quality deterioration due to unfavourable environmental and growing conditions depends largely on cultivar characteristics. Some foreign potato cultivars which were developed in the northern hemisphere are known to adapt poorly to local conditions, which may to some extent explain the poorer performance of Shepody and Pentland Dell.

Chip fry colour depends mainly on tuber concentrations of the reducing sugars glucose and fructose, prior to processing (Cottrell et al., 1995). The standard limit for reducing sugars for acceptable chipping quality is less than $0.2 \%$ on a fresh tuber mass basis. Higher concentrations cause chips to become unacceptably dark when fried (Cottrell et al., 1995). Results of this experiment revealed that reducing sugar levels were highest for Shepody $(0.183 \%)$, followed by Pentland Dell $(0.1 \%)$ and Frodo (0.067 \%) (Figure 1). Darius had the lowest reducing sugar content of $0.017 \%$. Although Shepody and Pentland Dell had values higher than those of the two new local cultivars, they were still below the USDA threshold of $0.2 \%$. However, when tubers of these cultivars are to be stored for long periods before processing, they may produce more reducing sugars, which will result in darker chip colours. It is, therefore, advisable to process these cultivars at harvest or shortly thereafter. On the other hand, the new cultivars, Frodo and Darius, contained less than $0.1 \%$ reducing sugars, which will result in acceptable light fry colours when processed, indicating that these cultivars easily meet the required quality standards for french fries and crisps.

Pentland Dell and Shepody are known for acceptably low reducing sugar levels and chip fry colours when grown in the environments where they were developed. Since reducing sugars are influenced by many factors other than cultivar characteristics, such as environment, cultural practices, soil and plant nutrient management (Stark et al., 2003), some of these factors could have influenced the foreign cultivars to accumulate higher reducing sugar levels under South African conditions. It is important to note, however, that if reducing sugar levels are too high at harvest, it is still possible to 
reduce them to acceptable levels through manipulation of early storage temperature (Stark et al., 2003).

An analysis of the TFI revealed that Frodo had significantly higher TFI values for the large and small tuber sizes, while Darius had consistently lower TFI values for all three tuber sizes (Table 3). Pentland Dell and Shepody, which are known for their oblong-shaped tubers (Van Niekerk, 1984;
Hutchinson et al., 2001), had similar intermediate TFI values for all tuber sizes. These results imply that Frodo has longer tubers that are more suitable for processing into fries, followed by both Pentland Dell and Shepody. Darius, on the other hand, tended to have more round tubers for all three tuber sizes, making them more suitable for processing into crisps.

Table 3 Average tuber form index (TFI) for large, medium and small sized tubers of four potato cultivars

\begin{tabular}{lccc}
\hline Cultivars & $\begin{array}{c}\mathrm{TFI}^{1} \\
\text { (large) }\end{array}$ & $\begin{array}{c}\text { TFI } \\
\text { (medium) }\end{array}$ & $\begin{array}{c}\text { TFI } \\
\text { (small) }\end{array}$ \\
\hline Frodo & $1.74 \mathrm{a}$ & $1.55 \mathrm{a}$ & $1.44 \mathrm{a}$ \\
Pentland Dell & $1.65 \mathrm{~b}$ & $1.53 \mathrm{a}$ & $1.33 \mathrm{~b}$ \\
Shepody & $1.64 \mathrm{~b}$ & $1.58 \mathrm{a}$ & $1.34 \mathrm{~b}$ \\
Darius & $1.47 \mathrm{c}$ & $1.41 \mathrm{~b}$ & $1.20 \mathrm{c}$ \\
\hline LSD $(0.05)$ & 0.085 & 0.085 & 0.075 \\
\hline $\mathrm{CV}(\%)$ & 2.8 & 2.1 & 2.9 \\
\hline
\end{tabular}

${ }^{1}$ Means in the same column followed by the same letter are not significantly different

Pentland Dell had significantly fewer large-sized tubers (Table 4). For medium tuber sizes, however, the difference between cultivars was not significant. On the other hand, Frodo had a significantly higher yield of small tubers than Shepody and Darius. A high total yield, with good fraction of large and medium sized tubers, is desirable for french fry processing. The total fresh tuber yield results also indicate that Shepody produced the lowest total tuber yield, compared to the other three cultivars (Table 4).

Table 4 Size distribution for large, medium and small tubers, as well as total tuber yield (Geremew et al., 2007) of four potato cultivars

\begin{tabular}{|c|c|c|c|c|}
\hline \multirow[b]{2}{*}{ Cultivars } & \multicolumn{4}{|c|}{ Fresh tuber yield (ton ha ${ }^{-1}$ ) } \\
\hline & Large $^{1}$ & Medium & Small & Total yield \\
\hline Frodo & $11.98 \mathrm{a}$ & $20.45 \mathrm{a}$ & $21.24 \mathrm{a}$ & $52.23 \mathrm{a}$ \\
\hline Pentland Dell & $3.94 b$ & $24.79 a$ & $13.30 \mathrm{ab}$ & $43.81 \mathrm{a}$ \\
\hline Shepody & $8.38 \mathrm{a}$ & $18.23 \mathrm{a}$ & $3.81 \mathrm{~b}$ & $25.07 b$ \\
\hline Darius & $9.58 \mathrm{a}$ & $25.39 a$ & $6.70 \mathrm{~b}$ & $40.84 a$ \\
\hline $\operatorname{LSD}(0.05)$ & 4.20 & 10.14 & 9.02 & 11.40 \\
\hline $\mathrm{CV} \%$ & 26.70 & 23.50 & 45.10 & 10.34 \\
\hline
\end{tabular}

${ }^{1}$ Means in the same column followed by the same letter are not significantly different

Table 5 summarises the external and internal tuber characteristics observed as part of the quality indicators. All the cultivars performed similarly with regard to secondary growth, resistance to mechanical damage and growth cracks. Similarly, with the exception of Shepody which had less than $10 \%$ malformed tubers, all the other cultivars were free of tuber malformations. Tuber malformations are known to occur if Shepody is exposed to unfavourable growing conditions, such as water and temperature stress (Visser, 2003). Cultivars Frodo and Darius were characterised by medium depth stolon indents, while the other cultivars had superficial stolon indents. Frodo and Shepody had medium eye depths and the other two cultivars had superficial eyes. Shallow stolon indents and eye depths are desirable for processing, as they both result in less off-cuts and wastage. In addition, Shepody and Darius possessed a white skin colour, whereas Pentland Dell and Frodo had yellow skins (Table 5). None of the observed external tuber characteristics were limiting for processing into french fries for any of the cultivars.

Results of the internal tuber characteristics are presented in Table 5 and Figure 2. For cultivars Frodo, Pentland Dell and Darius, less than $10 \%$ of the tubers were affected by dry rot, while Shepody was free of the defect (Table 5). Furthermore, none of the cultivars showed any symptoms of common scab and eelworm and all cultivars had a preferable white flesh colour.

With regard to vascular discolouration, Pentland Dell had the highest incidence, close to $30 \%$, followed by Shepody with $25 \%$ and Frodo with $20 \%$. Darius had a relatively low incidence of vascular discolouration of about $10 \%$ (Figure 2). Frodo showed the highest percentage of brown spot, about $20 \%$, followed by Darius and Pentland Dell, while Shepody had the lowest percentage, less than 5\% (Figure 2). Furthermore, Pentland Dell and Darius were free of hollow heart, 
while for Frodo and Shepody a small percentage of tubers were affected (Figure 2). Vascular discolouration, brown spot and hollow heart result from improper crop management during the growing period. Low soil water content, especially when the crop is close to maturity, or a rapid death of vines due to high temperature stress, can result in vascular discolouration (Pavlista, 2002). Growth disorders such as brown centre and hollow heart are mostly associated with abrupt changes in growing conditions during the season, for example rapid tuber growth after a cool period or after relieving water stress (Hochmuth et al., 2001). Irrigation, rainfall and soil water content measurements for this trial (data not presented) suggested that the potato crop was under irrigated during the last part of the growing season, due to technical problems experienced. This coincided with a period of high temperatures, which could have contributed to the reported internal defects.

Table 5 External and internal quality characteristics of four potato cultivars

\begin{tabular}{|c|c|c|c|c|}
\hline \multirow{2}{*}{ Quality Parameters ${ }^{1}$} & \multicolumn{4}{|c|}{ Cultivar score $^{2}$} \\
\hline & Frodo & Pentland Dell & Darius & Shepody \\
\hline \multicolumn{5}{|l|}{ External characteristics } \\
\hline Secondary growth (1-5) & 1 & 1 & 1 & 1 \\
\hline Malformation (1-5) & 1 & 1 & 1 & 2 \\
\hline Mechanical damage (1-5) & 2 & 2 & 2 & 2 \\
\hline Growth cracks (1-5) & 1 & 1 & 1 & 1 \\
\hline Stolon indent (1-3) & 2 & 1 & 2 & 1 \\
\hline Eye depth (1-3) & 2 & 1 & 1 & 2 \\
\hline Skin colour (1-5) & 3 & 3 & 1 & 1 \\
\hline \multicolumn{5}{|l|}{ Internal characteristics } \\
\hline Dry rot (1-5) & 2 & 2 & 2 & 1 \\
\hline Common scab area (1-5) & 1 & 1 & 1 & 1 \\
\hline Eelworm (Root knot)(1-5) & 1 & 1 & 1 & 1 \\
\hline Flesh colour (1-4) & 1 & 1 & 1 & 1 \\
\hline
\end{tabular}

\section{四 Vascular discolouration $\square$ Brown spot $\square$ Hollow heart}

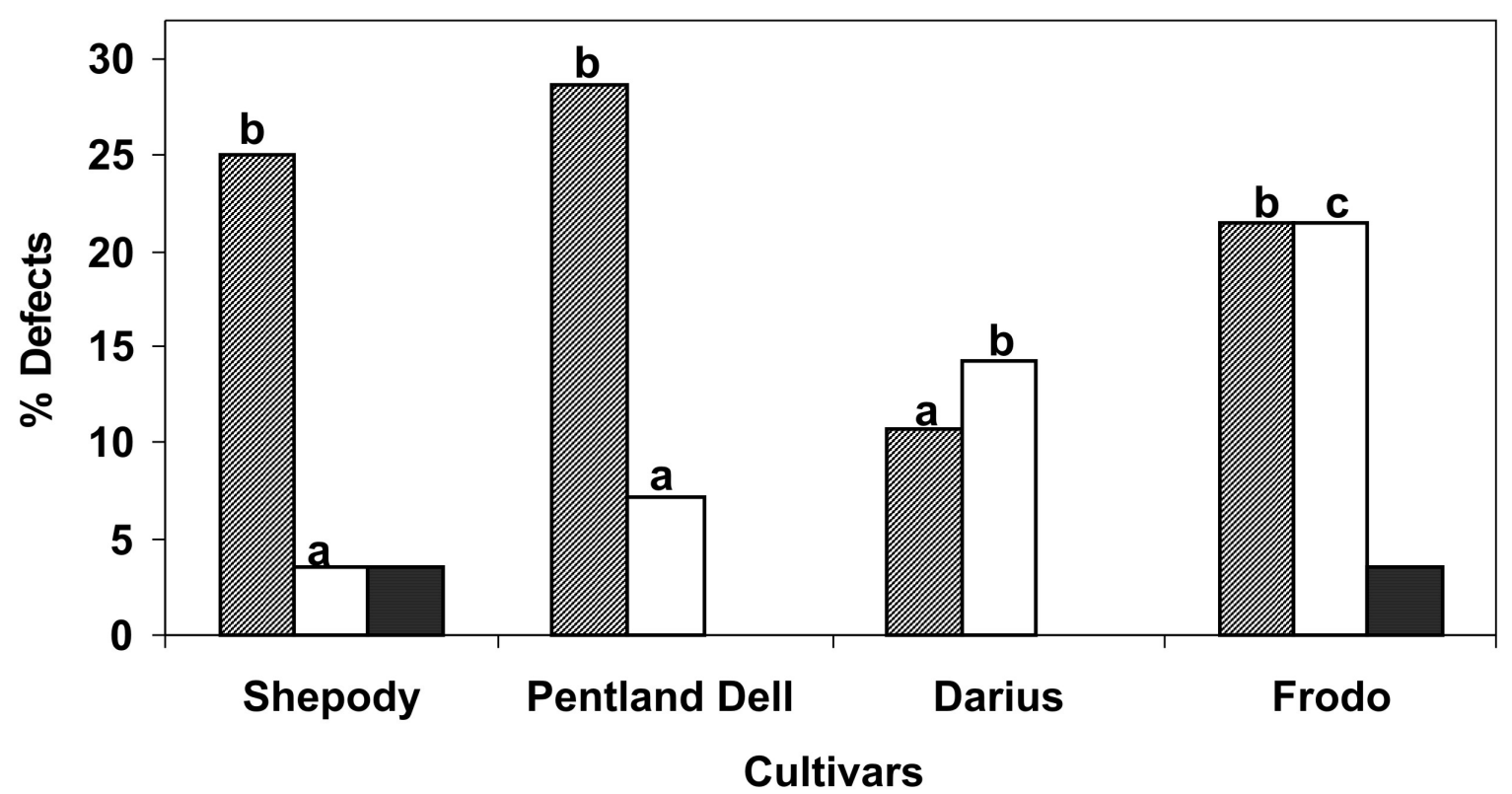

Figure 2 Vascular discolouration (\%), brown spot (\%), and hollow heart (\%) recorded for four potato cultivars 
Generally, the tuber quality parameters of cultivars investigated in this experiment were within acceptable limits for processing. Both new local cultivars appeared to have excellent internal and external tuber characteristics for processing.

\section{Conclusions}

The four potato cultivars tested achieved acceptable quality standards for most internal, external and processing quality characteristics. However, Pentland Dell and Shepody had the highest proportions of vascular discolouration and Frodo had a relatively high percentage of brown spot, presumably due to unfavourable growing conditions towards the end of the growing season.

Specific gravity of Shepody was far below the USDA standard for chipping quality, while Pentland Dell had intermediate SG values. Although within the limits of USDA standards, these cultivars also had relatively high reducing sugar levels, which may translate into darker fries. Frodo and Darius, on the other hand, had high specific gravities and low reducing sugars, which are ideal characteristics for quality frozen fries and long-term tuber storage. Frodo produced significantly more long-shaped tubers, which is ideal for french fry processing, while Darius had predominantly round tubers.

In general, internal and external tuber characteristic results followed the same trend as tuber yields, with Shepody's performance being significantly poorer than the other cultivars. These results suggest that Frodo and Darius were the most suitable for production of fries due to their high specific gravities, low reducing sugars and high tuber yields. These two new processing cultivars can, therefore, successfully compete with Shepody and Pentland Dell under local conditions.

\section{References}

BARITELLE, A.L. \& HYDE, G.M., 2003. Specific gravity and cultivar effects on potato tuber impact sensitivity. Postharvest Biol. Technol. 29, 279-286.

BELANGER, G., WALSH, J.R., RICHARDS, J.E., MILBURN, P.H. \& ZIADI, N., 2002. Nitrogen fertilization and irrigation affects tuber characteristics of two potato cultivars. Am. J. Potato Res. 17.

BROWN, C.R., 1993. Origin and history of potato. Am. Potato J. 70, 363-373.

COTTRELL, J.E., DUFFUS, C.M., PATERSON, L. \& MACKEY, G.R., 1995. Properties of potato starch: Effects of genotype and growing conditions. Phytochemistry 40, 1057-1064.

CSIDC, 2003. Processing potato in Saskatchewan: Potential and opportunities. Canada-Saskatchewan Irrigation Diversification Centre, 901 McKenzie St S, http://www.agr.ca. (Accessed 10/28/ 2005).

DAVID, W.W., FERERES, E. \& VOSS, R.E., 1983. Growth and yield response of two potato cultivars to various levels of applied water. Irrig. Sci. 3, 211-222.

GARY, D. \& HUGHES, J.C., 1978. The potato crop: The scientific basis of improvement. London: Chapman \& Hall.

GEREMEW, E.B., STEYN, J.M. \& ANNANDALE, J.G., 2007. Evaluation of growth performance and dry matter partitioning of four processing potato (Solanum tuberosum) cultivars. New Zeal. J. Crop Hort., 35, 385-393.

HAYES, R.J. \& THILL, C.A., 2002. Selection for potato genotypes from diverse progenies that combine $4{ }^{\circ} \mathrm{C}$ chipping with acceptable yields, specific gravity, and tuber appearance. Crop Sci. 42,
$1343-1349$.

HEGNEY, M., 2001. Specific gravity of potatoes. Farm note 48/ 1990, Department of Agriculture and Food, Western Australia. http://www.agric.wa.gov.au/content/hort/veg/cp/potatoes/ fn048_1990.htm. (Accessed 25/10/2005).

HOCHMUTH, G.J., HUTCHINSON, C.M., MAYNARD, D.N., STALL, W.M., KUCHAREK, T.A., WEBB, S.E., TAYLOR, T.G., SMITH, S.A. \& SIMONNE, E.H., 2001. Potato production in Florida. In: D.N. Maynard \& S.M. Olson (eds.). Vegetable production guide for Florida. Vance Publishing, New York.

HUDSON, D.E., 1975. The relationship of cell size, intercellular space, and specific gravity to bruise depth in potatoes. Am. Potato J. 52, 9-14.

HUTCHINSON, C.M., WHITE, J.M. \& WEINGARTNER, D.P., 2001. Fresh market white-skinned potato varieties for commercial production in Northeast Florida. http://edis.ifas.ufl.edu/ cv282 (Accessed 28/10/2005).

MCCANN, I.R. \& STARK, J.C., 1989. Irrigation and nitrogen management effects on potato brown center and hollow heart. Hort. Sci. 24, 950-952.

MOSLEY, A.R. \& CHASE, R.W., 1993. Selecting cultivars and obtaining healthy seed lots. p. 19-27. In: R.C. Rowe (ed.). Potato health management, APS Press, Minnesota, USA.

PAVLISTA. A., 2002. Skin set of tubers, an indication of maturity is a major reason for desiccating potato vines. Am. J. Potato Res. 79, 301-307.

SAS FOR WINDOWS, 2002. SAS Institute Inc., Cary, NC, USA.

SHETTY, K., 2005. Reviewing the procedure for specific gravity measurement of potato tubers. University of Idaho Potato Storage Research. http://www.kimberly.uidaho.edu (Accessed 10/25/ 2005).

SHOCK, C.C., FEIBERT, E.B.G. \& SAUNDERS, L.D. 1998. Potato yield and quality response to deficit irrigation. Hort. Sci. 33, 655659.

SOMSEN, D., CAPELLEB, A. \& TRAMPER, J. 2004. Manufacturing of par-fried French-fries. I. Production yield as a function of number of tubers per kilogram J. Food Eng. 61, 191-198.

STARK, J.C., OLSEN, N., KLEINKOPF, G.E. \& STEPHEN, L., 2003. Tuber quality in potato production systems. http://us.f356/ ym/ShowLetter?MsgId. (Accessed 30/01/2007).

STEYN, J.M., DU PLESSIS, H.F. \& NORTJE, P.F., 1992. Die invloed van verskillende waterregimes op Up-to-date aartappels. I. Vegetatiewe ontwikkeling, fotosintese tempo en stomatadiffusie-weerstand. (In Afrikaans with English abstract). S. Afr. J. Plant. Soil. 9, 113-117.

TOURNEUX, C., DEVAUX, A., CAMACHO, M.R. \& MAMANI, P., 2003. Effect of water shortage on six potato genotypes in the highlands of Bolivia. II. Water relations, physiological parameters. Agronomie 23, 181-190.

USDA, 1997. United States Standards for Grades of Potatoes for Chipping. Agricultural Marketing of Fruits and Vegetables as a Fresh Product. USDA. http://www.ams.usda.gov/standards/fzpo (Accessed 26/06/2005).

VAN NIEKERK, A.C., 1984. The cultivation of potatoes in South Africa. In: Farming in South Africa. http://lanra.anthro.uga.edu/ potato/Africa/safrica.htm (Accessed 13/01/2007).

VISSER, A.F., 2003. Selecting a suitable potato cultivar. In: J.G. Niederwieser (ed.). Guide to potato production in South Africa. ARC-Roodeplaat Vegetable and Ornamental Plant Institute, CPD Printers, Pretoria. 